\title{
Anticorpos Antifosfolípides e Perdas Gestacionais Recorrentes
}

\section{Antiphospholip Antibodies and Recurrent Fetal Losses}

Aos Editores: tomamos conhecimento da observação feita pelo colega ${ }^{(1)}$ relativa ao nosso estudo sobre a associação dos anticorpos antifosfolípides e perdas gestacionais, publicado na edição de jul/ago 2005, desse periódico ${ }^{(2)}$, e a esse respeito fazemos as seguintes considerações:

1. Reconhecemos a impropriedade do termo "prospectivo" utilizado no trabalho em avaliação, particularmente porque os casos foram prevalentes. Entretanto, nem todos os estudos caso-controle são retrospectivos. Se os casos forem incidentes, o estudo não poderia ser classificado como retrospectivo. Segundo Kleinbaum et a ${ }^{(3)}$ para considerarmos um estudo como retrospectivo é necessário que, no início da investigação, exposição e efeito já tenham ocorrido. Fica evidente que se os casos forem incidentes este critério não seria atendido;

2. Ainda quanto aos casos, esses podem ser considerados quanto à sua origem como incidentes ou prevalentes ${ }^{(4)}$. A utilização destes últimos é alternativa que favorece a obtenção do número previsto de casos, uma vez que o estudo casocontrole é indicado para investigar associações etiológicas em doenças de baixa incidência ou condições com período de latência prolongado ${ }^{(5)}$. Naturalmente, ao se incluir casos prevalentes, é necessária a devida atenção ao possível viés de recordação. Para Stolleye e Schlesselman ${ }^{(6)}$, é admissível a utilização de casos prevalentes quando os fatores estudados não alteram a duração ou o prognóstico da doença (história de perdas gestacionais), condição atendida pelo estudo em questão. Além disso, no trabalho em pauta, o interesse dos autores não foi estudar a perda fetal isolada, cujos casos poderiam ser incluídos quando do diagnóstico do óbito

\section{REFERÊNCIAS}

1. Cruz BA: Carta aos Editores. Rev Bras Reumatol 45: XXV, jul/ago, 2005.

2. Costa OLN, Brandão C, Silva MMR, Pimentel KS, Santiago MB: Anticorpos Antifosfolípides em Mulheres com Antecedentes de Perdas Gestacionais: Estudo caso-controle. Rev Bras Reumatol 45: 119-23, 2005.

3. Kleinbaum DO, Kupper LL, Morgenstem R: Statistical Inferences About Effect Measures: Simple Analysis In Epidemiologic intra-uterino, e sim uma condição complexa, que foi a perda gestacional de repetição. Assim, ao investigarmos pacientes com antecedentes (história) de perdas gestacionais, inevitavelmente, teríamos que trabalhar com casos prevalentes.

3. Nosso interlocutor defende a posição de que o estudo caso-controle com casos incidentes permite estabelecer a sequiência temporal entre exposição e efeito. Contudo, é fácil verificar que, no nosso estudo, se pudéssemos trabalhar com casos incidentes, isso não garantiria a determinação dessa seqüência, desde que somente após a detecção de um caso de perda é que seria realizada a pesquisa dos anticorpos, porque esta não é feita rotineiramente.

Agradecemos a contribuição recebida, pois entendemos que esse debate é precioso para o aperfeiçoamento do nosso conhecimento científico.

Olívia Lúcia Nunes Costa

Departamento de Ginecologia, Obstetrícia e Reprodução Humana, Universidade Federal da Bahia (UFBA).

Cláudio Brandão Hospital Aliança, Salvador, BA.

Mônica Maria Ribeiro Silva Maternidade Climério de Oliveira, UFBA.

Kleber Santos Pimentel Maternidade Climério de Oliveira, UFBA.

Mittermayer Barreto Santiago Núcleo de Reumatologia da Bahia, Escola Bahiana de Medicina e Saúde Pública, Salvador, BA.

Research; Van Nostrand Reinhold, New York, 1982.

4. Almeida Filho N, Rouquayrol MZ: Elementos de Metodologia Epidemiológica. In Epidemiologia \& Saúde $6^{\mathrm{a}}$ Edição Medsi Editora Médica e Científica Ltda, Rio de Janeiro, 2003.

5. Pereira MO: Métodos Empregados em Epidemiologia In Epidemiologia Teoria e Prática Ed. Guanabara Koogan, Rio de Janeiro, 1995.

6. Stolley PD, Schlesselman JJ: Planning and Conducting a Study In Case-contraI Studies: Schlesselman JJ, Oxford University Press, New York, 1982. 